\title{
Importância dos arquivos empresariais para a pesquisa histórica em Administração no Brasil
}

\author{
Relevance of business archives to the historical research on Management in Brazil
}

Diego Maganhotto Coraiola ${ }^{1}$

\begin{abstract}
Resumo
Nos últimos anos, verificam-se crescente consciência e preocupação dos pesquisadores da área de Estudos Organizacionais com relação à importância da História e do desenvolvimento de pesquisas históricas para a compreensão dos objetos de estudo da disciplina. No entanto, qualquer pesquisa que se dedique a resgatar traços de situações, eventos e acontecimentos passados estará, necessariamente, restrita às reminiscências desse período. Dessa forma, qualquer clamor pela descoberta do passado precisa estar acompanhado de outro, que demanda também a preservação e disponibilização dos vestígios e fontes que lhe proporcionem acesso. Defende-se, como argumento central deste trabalho, a necessidade de discussão e avaliação da atual situação dos arquivos empresariais brasileiros, a fim de promover o desenvolvimento de ações e projetos de melhoria voltados à preservação e disponibilização de arquivos empresariais para a pesquisa na área de Estudos Organizacionais. Assim, o interesse no fortalecimento dos programas de preservação e dos empreendimentos dedicados aos arquivos empresariais brasileiros demanda que sejam equacionadas as possibilidades de contribuição de agentes públicos e privados. Estes integrariam seus esforços na construção de projetos e programas dedicados a recuperar documentos e registros sobre a história das organizações brasileiras, reunir e organizar adequadamente esses registros em coleções e arquivos bem estruturados, além de disponibilizar os acervos das diversas instituições dedicadas aos arquivos empresariais para a realização de pesquisas. Essa é uma etapa necessária e fundamental para garantir a disponibilidade de matéria-prima para pesquisas dedicadas a desvendar a história das empresas e do desenvolvimento da Administração no Brasil.
\end{abstract}

Palavras-chave: Arquivos empresariais. Pesquisa histórica. Estudos organizacionais. Administração. Fontes históricas. Historiografia.

\begin{abstract}
In the last couple of years, there has been a growing concern of researchers from the field of Organization Studies with regard to the importance of History and the development of historical researches aiming to understand the study object of this discipline. However, any research trying to recover evidence from past situations, events, and happenings will necessarily be restricted to the reminiscences of that time. Thus, any clamor for discovering the past needs to be followed by another one, also demanding the preservation and availability of traces and sources which give it some point of entry. One may claim as the main argument of this paper the need for discussing and evaluating the current status of the Brazilian business archives, in order to promote the development of actions and projects to improve the preservation and availability of business archives to researches in the field of Organization Studies. Therefore, the interest in strengthening preservation programs and initiatives dedicated to the Brazilian business archives requires determining the possibilities of contribution from public and private agents. They might join their efforts to develop projects and programs dedicated to recover documents and records about the Brazilian organizations, properly gather and organize these records into well-structured collections and files, as well as provide researchers with access to the collections of the many institutions dedicated to keep business archives. This is a necessary and crucial step to guarantee the availability of raw material for researches aiming to unveil the history of companies and the development of Management in Brazil.
\end{abstract}

Keywords: Business archives. Historical research. Organization studies. Management. Historical sources. Historiography.

1 Doutorando em Administração pela Universidade Federal do Paraná - UFPR; Professor do Centro Universitário Curitiba UNICURITIBA. Endereço: Universidade Federal do Paraná - UFPR, Avenida Pref. Lothario Meissner, 632, 2ํ․ Andar, Jardim Botânico, CEP 80210-170, Curitiba - PR, Brasil. E-mail: dcoraiola@gmail.com 


\section{Introdução}

Nos últimos anos, verificam-se crescente consciência e preocupação dos pesquisadores da área de Estudos Organizacionais com relação à importância da História e do desenvolvimento de pesquisas históricas para a compreensão dos objetos de estudo da disciplina. Entre os principais trabalhos que defendem a necessidade de aproximação entre os quadros conceituais da história e dos Estudos Organizacionais, destacam-se produções de autores nacionais e internacionais. De maneira geral, é possível dividi-los em três grandes grupos: o primeiro defende a incorporação da História enquanto perspectiva analítica, o segundo destaca a relevância do método historiográfico, e o terceiro considera a história, ou histórias, enquanto objeto de análise.

O primeiro grupo busca a incorporação da História como perspectiva analítica nos estudos organizacionais, defendendo a necessidade de se compreender a organização como fenômeno situado historicamente, assim como as pesquisas realizadas sobre o assunto. O segundo grupo defende a necessidade e a contribuição que pode ser agregada por meio da adoção da historiografia, ou dos métodos de pesquisa histórica, para a realização de análises sobre fenômenos organizacionais. O terceiro grupo objetiva mostrar a importância de se trazer para o âmbito das pesquisas em Administração outros objetos de estudo e formas de pesquisa como aquelas desenvolvidas sob a abordagem da Business History, normalmente traduzida como História Empresarial ou História de Negócios.

Apesar da grande importância assumida pelas questões históricas nesses trabalhos, poucos são aqueles que se dedicam a discutir a questão das fontes históricas e do acesso dos pesquisadores aos arquivos históricos uma exceção é o trabalho de Dalla Costa (2004). Qualquer pesquisa que se dedique a resgatar traços de situações, eventos e acontecimentos passados estará, necessariamente, restrita às reminiscências que desse período foram preservadas. Estejam inscritos em documentos ou artefatos ou sejam ainda componentes da memória individual ou coletiva, estes fragmentos históricos são fonte única de acesso a um passado em contínuo distanciamento e obscurecimento. Dessa maneira, qualquer clamor pela descoberta do passado precisa estar acompanhado de outro, que demanda também a preservação e disponibilização dos vestígios e fontes que lhe proporcionam acesso (PIERANTI, 2008; TUCHMAN, 1998).

Em países como Alemanha, Suíça e Holanda, a preocupação com a criação de estruturas dedicadas à coleta e preservação de informações e documentos das empresas teve início logo no primeiro quarto do século XX, enquanto em outros, como Estados Unidos, França e Inglaterra, a instalação de arquivos similares sucedeu-se somente após a II Guerra Mundial. Ainda em outras nações, iniciativas estruturadas de preservação sistemática de documentos e arquivos de empresas seriam desenvolvidas somente após os anos de 1960, como é o caso da Itália e da Espanha e também de outras nações sul-americanas, como o Brasil. Entre os modelos originados nestes países, percebe-se que há os que se sustentam, por um lado, no interesse das próprias empresas em preservar a sua história e, por outro, na atuação centralizada de instituições públicas (TORTELLA, 2003).

Desse modo, seja em razão do curto espaço de tempo que demarca o início da construção de políticas públicas voltadas à criação de uma estrutura dedicada à preservação dos arquivos brasileiros, seja por influência da falta de tradição das empresas nacionais em manter preservados os arquivos relativos à sua história, ou ainda em decorrência da intervenção de outros fatores acessórios e correlatos, fato é que o campo de arquivos empresariais no Brasil ainda compreende área muito pouco explorada na literatura acadêmica e também possui expressividade muito pequena quando considerados os empreendimentos arquivísticos dedicados a desenvolver as práticas de resgate, gestão e disponibilização de registros e informações relativos à história das empresas no País.

Em se considerando o quadro apresentado, argumenta-se que para, que sejam factíveis os apelos dos pesquisadores acerca da necessidade de maior reflexividade histórica por parte das pesquisas em Administração e da possibilidade de incorporação das questões históricas e do método histórico nos estudos organizacionais, torna-se fundamental colocar em pauta discussão acerca da existência e disponibilidade de 
arquivos empresariais ou, de modo mais amplo, de arquivos de negócios (business archives) ${ }^{2}$, referentes à atuação das empresas brasileiras nacional e internacionalmente, bem como das empresas estrangeiras em solo nacional. Esse é o propósito que orienta a construção deste artigo, no qual se pretende analisar a questão essencial da atual situação dos arquivos empresariais brasileiros em termos de estrutura, legislação e de sua disponibilidade para pesquisa e para consulta pública.

\section{Estudos Organizacionais e História Empresarial}

A importância da história para a compreensão das organizações não se trata de descoberta ou fenômeno recente. Os primeiros estudos sociológicos que se dedicaram à análise das organizações já haviam compreendido a necessidade de se contextualizar historicamente o fenômeno de surgimento e proliferação das organizações como uma característica das sociedades modernas. No que concerne aos trabalhos escritos sob a incipiente disciplina de Administração, havia também considerações sobre a necessidade de conhecimento da História para o estudo das empresas e das práticas administrativas, assim como para a criação de um corpo de conhecimentos e estratégias adequado para o ensino de administração (SCOTT, 2003; WEBER, 1998).

A proximidade inicial existente entre a História e as pesquisas sobre organizações persistiu até quase a metade do século XX. Desse período em diante é possível distinguir a consolidação de duas disciplinas distintas: Estudos Organizacionais (Organization Studies) e História de Negócios (Business History). Os Estudos Organizacionais, em conjunto com as preocupações de sociólogos e economistas em estabelecerem as bases científicas de suas disciplinas, passam a empregar metodologias quantitativas e vinculam-se a princípios de cientificidade neopositivistas. A ênfase dos pesquisadores se distancia dos aspectos mais maleáveis e não corroboráveis originários das metodologias históricas para a análise e mensuração do relacionamento entre as variáveis organizacionais e seus aspectos contextuais, visando distinguir padrões e realizar generalizações (KIPPING e ÜSDIKEN, 2008; ÜSDIKEN e KIESER, 2004).

A disciplina de História de Negócios ou História Empresarial, como a Business History é comumente traduzida para outras línguas, também tem sua origem no seio daquele relacionamento entre História e organizações. No entanto, diferentemente de Estudos Organizacionais, ela manteve sua vinculação com a disciplina-mãe de História Econômica. A orientação epistemológica predominante permaneceu sendo aquela da História, associada aos ideais da história narrativa e utilizando-se de procedimentos historiográficos de pesquisa. Sob essa abordagem, são desenvolvidos diversos estudos dedicados a compreender o surgimento e a evolução das empresas e empresários com base na comparação entre empresas de um mesmo período e uma mesma sociedade ou de períodos e sociedades distintas (CAMPELLO, 2005; COLE, 1962; MENDES, 2002; ROBERTS, 2003).

Apesar de a História Empresarial ter-se constituído como disciplina distintiva, sua influência sobre outras disciplinas foi sempre periférica e sua relação, normalmente, de subordinação. Em boa parte decorrente do desdobramento cientificista na área econômica, eram comuns as considerações quanto à carência de conjunto de fundamentos teóricos e ferramentas interpretativas que permitissem à História Empresarial compreender o desenvolvimento organizacional ao longo do tempo. Dessa maneira, as pesquisas realizadas sob aquela abordagem funcionavam como "[...] mero campo de pruebas de la teoría y el historiador, si no era teórico, sería una especie de ayudante de investigación para el economista" (VALDALISO e LÓPEZ, 2003, p. 43).

2 No presente trabalho, os termos "arquivos empresariais", "arquivos de empresas", "arquivos organizacionais" e "arquivos de negócios" serão tratados como sinônimos. 
Considerando esse histórico, surpreende a recente expansão no número de adeptos da perspectiva da História Empresarial nos mais variados centros de pesquisa nacional e internacional. Entre as causas aventadas para a ocorrência desse fenômeno, destacam-se: a proliferação na quantidade de pesquisas e publicações dedicadas a discutir o assunto; o reconhecimento da importância do papel desempenhado pelas organizações na economia e sociedade contemporâneas, em boa parte decorrente do descrédito de algumas explicações propagadas por certas vertentes marxistas quanto à influência perniciosa do empresariado ao desenvolvimento e à riqueza das sociedades; e a percepção de proprietários e administradores de empresas quanto às vantagens da manutenção da memória e do patrimônio históricos da empresa para o desenvolvimento de campanhas de marketing e para a gestão da identidade organizacional (MENDES, 2002; VALDALISO e LÓPEZ, 2003).

Mais recentemente, pode-se destacar como fatores adicionais de contribuição para o aumento na quantidade de trabalhos relacionados com a história das empresas a atenção renovada que alguns autores têm dado ao emprego de perspectiva histórica para o estudo das organizações e o manifesto interesse na aproximação entre História Empresarial e Estudos Organizacionais. Esse fenômeno vem sendo tratado na literatura especializada como uma guinada dos estudos organizacionais em direção à história (historical turn) (CLARK e ROWLINSON, 2004). E, também, entre outros fatores, teria relação com o declínio do ensino de história econômica, que impeliu boa parte dos historiadores de negócios a migrarem dos departamentos de História e Economia para as escolas de Administração e negócios (HARVEY e WILSON, 2007).

A visão pioneira de N. S. B. Gras (1938) já havia compreendido como propósito da História Empresarial o estudo do desenvolvimento da Administração. E, se as preocupações seguintes de Cole (1962) se voltam ao estudo dos aspectos estruturais e da mudança em Organizações com vistas ao desenvolvimento de história geral, que possui como expressão máxima a revolução promovida pelos trabalhos de Alfred Chandler (1962, 1977, 1990), existem outros mais interessados em algo próximo a uma sociologia histórica da Administração (COCHRAN, 1962). No contexto brasileiro, vale destacar as pesquisas sobre industrialização do Brasil (CARDOSO, 1964; BRESSER PEREIRA, 1974), o desenvolvimento da área de História Econômica (LEVY, 1977; 1994; SZMRECSÁNYI, 2004) e as preocupações originais de Guerreiro Ramos (1983) com a teorização acerca dos aspectos sócio-históricos das organizações brasileiras. Os últimos anos também têm sido marcados pelo fortalecimento de iniciativas como as da Associação Brasileira de Pesquisadores em História Econômica, responsável pela Conferência Internacional de História das Empresas, assim como pela proliferação de ensaios e estudos que reforçam aquela aproximação entre História e Estudos Organizacionais (COSTA, BARROS e MARTINS, 2009; MARTINS, 2001; VIZEU, 2007; 2010). ${ }^{3}$

Seguindo-se a esse processo, e como elemento partícipe do próprio fenômeno de mudança e transformação dos estudos organizacionais, é possível tentar separar analiticamente alguns grupos de pesquisadores em suas preocupações e argumentos em favor da utilização ou consideração da História quando dos estudos sobre organizações. Ainda que não exista uma séria divisão entre as propostas ou quaisquer considerações a respeito de serem excludentes ou complementares, as justificativas dos autores em prol dessa aproximação podem ser agrupadas em três conjuntos de argumentos que contribuem para o desenvolvimento de diferentes práticas de pesquisa considerando a transversalidade entre a História e o fenômeno organizacional.

O primeiro conjunto de argumentos compreende a necessidade de se incorporar a História como perspectiva analítica ao próprio quadro teórico de referência de determinada abordagem. A História, assim como outras categorias analíticas fundamentais de determinado corpus teórico, deveria ser compreendida em suas conexões e influências com relação às demais categorias, bem como sua relevância e potencial explicativo deveriam ser teorizados e analisados empiricamente. Essa abordagem entende as organizações, antes de tudo, como fenômenos historicamente situados e busca compreender, por um lado, a influência do contexto e dos

\footnotetext{
${ }^{3}$ Agradecemos as observações dos avaliadores quanto à necessidade de destacar que a preocupação em concatenar Estudos Organizacionais e História não se trata de invenção estrangeira ou de novidade recente.
} 
acontecimentos históricos no percurso de desenvolvimento dessas empresas e, por outro, a historicidade das estruturas e processos organizacionais (KIPPING e ÜSDIKEN, 2008; ÜSDIKEN e KIESER, 2004; ZALD, 1989). No esteio dessa proposta pode ser localizada também perspectiva que sugere a análise da Administração enquanto instituição característica da modernidade (COCHRAN, 1962; COSTA, BARROS e MARTINS, 2009; VIZEU, 2007; 2010).

O segundo conjunto de escritos se distancia da visão da História enquanto perspectiva analítica e propõe que a maior contribuição desta área envolva o fornecimento de um conjunto de metodologias para a análise das organizações. Mais especificamente, os autores que defendem esse ponto de vista normalmente indicam a importância da realização de pesquisas históricas ou que utilizam os métodos da historiografia à análise das organizações. Em se tratando exclusivamente das propostas cujo foco é a questão metodológica, normalmente as contribuições recaem na recomendação quanto à possibilidade de utilização dos métodos de análise documental e de história oral para a realização dos trabalhos de pesquisa (BOOTH e ROWLINSON, 2006; CURADO, 2001; ICHIKAWA e SANTOS, 2006; PIERANTI, 2008; VIZEU, 2007; 2010).

No terceiro grupo de argumentos, considera-se a História enquanto fator, variável ou objeto de estudo. Nesse caso, seria mais acertado tratar de histórias em vez de história. Essa perspectiva se aproxima bastante do caso exemplar dos trabalhos desenvolvidos sob a égide daquela disciplina de História Empresarial, para a qual o principal objeto de análise encerra-se na própria História, seja ela a história de uma empresa, de um grupo de empresas ou de um empreendedor. A diferença que pode existir, e de certa forma manter distintas essas duas propostas, consiste na manutenção do método científico e dos princípios de análise originários das tradições teóricas dos estudos organizacionais (KIESER, 1994; KIPPING e ÜSDIKEN, 2008; LAWRENCE, 1984; MENDONÇA, 2001).

Como se pode perceber nas citações apresentadas no texto, as manifestações favoráveis à aproximação entre História e Estudos Organizacionais não são somente estrangeiras. No que concerne à realidade brasileira, verifica-se também a preocupação dos pesquisadores com questões relacionadas à necessidade de incorporar elementos da disciplina ao quadro teórico de referência e aos procedimentos metodológicos utilizados para o desenvolvimento dos estudos sobre organizações. Nesse caso, além das dificuldades inerentes à incipiência desse movimento entre os acadêmicos brasileiros da área de Administração, é possível constatar que os autores apontam também como empecilho para realizar esse tipo de pesquisa outros fatores, geralmente relacionados com a falta de interesse e precariedade das estruturas de preservação do patrimônio histórico e arquivístico brasileiro.

Entre as principais críticas e observações realizadas pelos autores em seus trabalhos, destacam-se: o desconhecimento ou desinteresse do empresariado em preservar documentos e arquivos, a fragilidade estrutural das instituições dedicadas à preservação dos registros e informações, a ausência ou perda de documentos ou arquivos sobre o assunto de interesse ou mesmo a falta de acesso aos documentos e materiais demandados pela pesquisa (DALLA COSTA, 2004; PIERANTI, 2008; VIZEU, 2008). O elemento comum que permeia as dificuldades apontadas para a realização de pesquisas históricas sobre organizações sustenta o argumento central deste trabalho, que defende a necessidade de discussão e avaliação da atual situação dos arquivos empresariais brasileiros a fim de promover o desenvolvimento de ações e projetos de melhoria voltados à preservação e disponibilização de arquivos para a pesquisa na área de Organizações.

\section{Situação Geral dos Arquivos Empresariais no Brasil}

Comparativamente a países como Alemanha, França e Estados Unidos, a preocupação brasileira com a preservação de elementos patrimoniais, de arquivo, bem como outros tipos de artefatos e informações referentes às empresas atuantes em solo nacional é bastante recente, sendo possível identificar esforços pioneiros, conscientes e sistemáticos nesse sentido somente em meados da década de 1960. Esse período é contemporâneo dos primeiros estudos sobre história de negócios no País e ocorre em paralelo a momento em 
que outras regiões da América Latina desenvolveram também preocupações relativas à questão das empresas e do empresariado industrial.

Esses estudos foram motivados pela tentativa de compreender os aspectos relacionados às questões de desenvolvimento econômico e da formação sócio-econômica brasileira. Autores como Bresser Pereira, Fernando Henrique Cardoso, Caio Prado Jr. e Warren Dean são exemplares dessa fase da historiografia econômica nacional. Posterior a esse período breve, a temática da industrialização brasileira cedeu espaço para outros objetos de pesquisa na área de Ciências Sociais. Isso não encerrou a trajetória dos estudos históricos sobre as empresas no Brasil, que apesar de terem sido quase abandonados pelos sociólogos, permaneceram sendo desenvolvidos nas faculdades de Economia e História (CAMPELLO, 2005; FORJAZ, 2008).

Apesar de breves, essas iniciativas tiveram certa contribuição com relação à consciência sobre a necessidade de desenvolvimento de legislação e programa voltados à preservação da documentação e dos arquivos nacionais. $\mathrm{O}$ amadurecimento da discussão sobre a questão dos arquivos públicos e privados no Brasil redundou na promulgação da Lei ${ }^{\circ}$ 8.159, em 08 de janeiro de 1991. Entre os principais pontos da Lei de Arquivos, como ficou conhecida, é possível destacar: a diferenciação entre arquivos públicos e privados; a incorporação da noção de ciclo de vida documental, com a diferenciação entre documentos correntes, intermediários e permanentes; e a criação do Conselho Nacional de Arquivos (CONARQ), órgão central do Sistema Nacional de Arquivos (SINAR), responsável pela definição da política nacional de arquivos públicos e privados (BRASIL, 1991).

De acordo com aquele documento, o poder público é responsável pela gestão e proteção de documentos que sirvam de suporte para a administração, cultura, desenvolvimento científico e que configurem elementos de prova ou informação. A Lei ${ }^{\circ} 8.159$ define ainda o que se entende por arquivos, compreendendo-os como "os conjuntos de documentos produzidos e recebidos por órgãos públicos, instituições de caráter público e entidades privadas, em decorrência do exercício de atividades específicas, bem como por pessoa física, qualquer que seja o suporte da informação ou a natureza dos documentos" (BRASIL, 1991, s. p.).

A Lei de Arquivos também distingue entre arquivos públicos e privados: os primeiros são produto das atividades de órgãos públicos ou órgãos privados responsáveis pela gestão de serviços públicos, enquanto os últimos configuram documentos relativos às atividades de pessoas físicas ou jurídicas de direito privado. A Lei ainda prevê que os arquivos privados poderão ser declarados de interesse público e social, na medida em que "[...] sejam considerados como conjuntos de fontes relevantes para a história e desenvolvimento científico nacional" (BRASIL, 1991, s. p.). O Decreto $\mathrm{n}^{\circ}$ 4.073, de 3 de janeiro de 2002, que regulamenta a Lei de Arquivos, especifica que essa declaração é realizada por meio de decreto presidencial e no $\S 1^{\circ}$ de seu artigo 22, estabelece que "a declaração de interesse público e social de que trata este artigo não implica a transferência do respectivo acervo para guarda em instituição arquivística pública, nem exclui a responsabilidade por parte de seus detentores pela guarda e a preservação do acervo" (BRASIL, 2002, s. p.).

Desse modo, enquanto a administração dos documentos públicos, ou daqueles que possuem caráter público, é de competência das instituições arquivísticas públicas (federais, estaduais, do Distrito Federal e municipais), aos proprietários de arquivos privados cabem a guarda e preservação dos acervos sob sua custódia, mesmo daqueles declarados de interesse público e social, podendo responder em instância penal, civil ou administrativa pela desfiguração ou destruição de documentos de caráter permanente. Em razão disso, a norma orienta que os particulares poderão estabelecer acordos com o CONARQ ou outras instituições que lhes permitam obter apoio para o desempenho de atividades de organização, preservação e divulgação do acervo (BRASIL, 2002).

Vale destacar que, ainda que os arquivos privados sejam declarados de interesse público, o proprietário ou possuidor do acervo precisa permitir seu acesso ou, como registra o documento oficial, franquear a eles o acesso (BRASIL, 1991). Nesse sentido, embora seja possível registrar vários avanços na legislação brasileira sobre arquivos, ainda é incipiente a discussão sobre as normas que regulamentam o acesso aos arquivos 
públicos e privados para a realização de pesquisas. Diferentemente de alguns países, nos quais existem políticas de fomento à constituição de arquivos privados e incentivos para a abertura destes à consulta pública e realização de pesquisas acadêmicas - tipo de prática que ainda carece de muito debate e investimento em solo nacional (COSTA, 2003; JARDIM, 1999).

A indicação de possibilidades ainda a serem desenvolvidas não deve obliterar o pioneirismo brasileiro, diante de outros países latino-americanos, na criação de uma lei geral e de um sistema nacional de arquivos. Esse pioneirismo, conforme aventa a Fundación Histórica Tavera (1999), pode ter contribuído para a relativa posição de destaque ocupada pelo País na produção de trabalhos acadêmicos sobre História Econômica e, em menor grau, História Empresarial. Há de se ver, no entanto, que os avanços na dimensão legislativa encobrem também algumas grandes dificuldades e deficiências presentes em relação à dimensão material e de gerenciamento dos arquivos existentes. Por um lado, verifica-se que até o presente momento não foi viabilizado o funcionamento do Sistema Nacional de Arquivos e nem foi implementada política nacional de arquivos pelo CONARQ (JARDIM, 2011). Por outro, constata-se grandes dificuldades na gestão e operacionalização dos arquivos, principalmente em nível estadual e municipal.

Ao longo dos seus doze primeiros anos, entre 1994 e 2006, o plenário do CONARQ reuniu-se quarenta vezes. Em nenhuma dessas reuniões o tema da implantação de uma política nacional de arquivos esteve contemplado na pauta de reunião. Os principais temas debatidos nesses encontros foram relativos a normas e à legislação arquivística, além de assuntos relativos ao próprio CONARQ, evidenciando poucos esforços voltados ao estabelecimento de políticas públicas informacionais e arquivísticas (JARDIM, 2008). Associada à ausência de política nacional de arquivos e demais políticas públicas de fomento à criação, desenvolvimento e integração dos arquivos nacionais na agenda de preocupações, está é a atual situação dos arquivos brasileiros, cujos diagnósticos apontam grande precariedade em termos de estrutura e recursos, além de "[...] progressiva corrosão da situação arquivística" (JARDIM, 1999, s. p.).

Apesar dos avanços verificados na gestão dos arquivos federais no final da década de 1980, ainda são problemáticos o controle dos itens em acervo e o acesso às informações existentes. Nas outras esferas do poder público, como estados e municípios, os problemas assumem dimensões ainda maiores. Nesses âmbitos, não é rara a inexistência de política de recolhimento sistemático de documentos ou mesmo o acúmulo de volumes de documentos sem qualquer tipo de análise ou organização. Os diagnósticos elaborados sobre a situação dos arquivos nacionais nos últimos vinte anos apontam sérios problemas relacionados à fragilização dos acervos, como perda de documentos acumulados e documentos em processo, até a precarização das instalações e equipamentos e falta de pessoal. Isso acarreta sérias consequências para a preservação da história nacional e implica uma série de barreiras ao acesso à informação pública (BELÉM, 2009; JARDIM, 1999; 2008).

Entre os maiores problemas identificados com relação aos arquivos brasileiros, está, em primeiro lugar, a falta de recursos materiais e humanos para realizar as atividades arquivísticas. Não se trata de problema restrito do Brasil, mas de situação crônica identificada em toda a América Latina. Essa carência se manifesta de forma desigual e desproporcional pelas regiões do País, com menor incidência de problemas nas regiões mais ao Sul e maior ocorrência de dificuldades no Norte e Nordeste do País. O desequilíbrio permanece em relação às esferas de governo, havendo mais falta de recursos no âmbito municipal do que na esfera federal (ARAÚJO e BATALHA, 1999; FUNDACIÓN HISTÓRICA TAVERA, 1999).

En Brasil, al igual que en Argentina y en otros países donde se está elaborando el informe, uno de los principales problemas de los archivos es su dependencia de otras entidades que son las que en último caso determinan las políticas a seguir, una serie engorrosa de gestiones burocráticas para conseguir y gestionar recursos para su propio archivo. En muchas ocasiones el responsable del archivo no interviene en la elaboración final de su propio presupuesto. (FUNDACIÓN HIISTÓRICA TAVERA, 1999, p. 22). 
Além da ausência de recursos públicos, outra situação bastante problemática diz respeito ao desconhecimento dos arquivos. No relatório da Fundación Histórica Tavera (1999), indica-se desconhecimento da realidade dos arquivos públicos localizados nos estados e municípios brasileiros, assim como das instituições arquivísticas detentoras de arquivos privados no País. Sabe-se que essa situação sofreu algumas mudanças nesses últimos onze anos, mas as alterações não foram suficientes a ponto de criar uma nova realidade para os arquivos do País. Em pesquisa realizada sobre as dificuldades encontradas na implantação dos arquivos estaduais no Brasil, Belém (2009) afirma que a origem da maioria das barreiras encontradas está relacionada a questões culturais e históricas como a falta de conscientização sobre a importância dos arquivos e sobre a otimização dos serviços públicos.

A mesma observação escrita naquele relatório com relação aos arquivos eclesiásticos pode ser estendida hoje aos arquivos empresariais:

[...] no existe ninguna asociación a nivel nacional o estadual, que se ocupe de la coordinación de proyectos relacionados con su patrimonio documental, ni tampoco de la interrelación de estos archivos brasileños. Cualquier actuación orientada a estos fines, responde a acciones individuales llevadas a cabo por los responsables de los archivos eclesiásticos. La mayor parte de los convenios de colaboración desarrollados por estos archivos están realizados con centros universitarios religiosos y también públicos. (FUNDACIÓN HISTÓRICA TAVERA, 1999, p. 10).

Com base nesse relatório e em outras avaliações efetuadas, foram desenvolvidas ações visando à melhoria da gestão dos arquivos públicos brasileiros. A Lei de 08 de janeiro de 1991 já havia trazido diversas contribuições para regulamentar e definir um sistema adequado e integrado para a gestão nacional de arquivos. Com a promulgação do Decreto $\mathrm{n}^{\circ} 4.073$, em 3 de janeiro de 2002, foi realizada a regulamentação daquela Lei de Arquivos e criada uma política nacional de arquivos públicos e privados. Por fim, com a edição da Resolução $\mathrm{n}^{\circ}$ 19, de 28 de outubro de 2003, o governo estabeleceu as normas relativas aos acervos das empresas públicas em processo de privatização e as obrigações das empresas privadas que as sucedem para com esses arquivos.

Além dessas contribuições, a legislação instituiu uma série de grupos destinados a realizar a avaliação da situação dos arquivos no País e a propor um conjunto de ações, normas e regulamentações necessárias para o desenvolvimento dos arquivos em âmbito nacional. Foram criadas cinco câmaras técnicas responsáveis por esse trabalho: Normalização da Descrição Arquivística; Documentos Eletrônicos; Conservação de Documentos; Gestão de Documentos; e Capacitação de Recursos. Além das câmaras técnicas, foram definidas também câmaras setoriais, ou temáticas, de acordo com os principais tipos de arquivo que se pretendia preservar. São em número de sete as câmaras técnicas: Arquivos do Judiciário; Arquivos Médicos; Arquivos de Arquitetura, Engenharia e Urbanismo; Arquivos Municipais; Documentos Audiovisuais, Iconográficos e Sonoros; Arquivos Privados; e Arquivos de Empresas Privatizadas ou em Processo de Privatização.

Um grande avanço para os arquivos nacionais foi obtido com o desenvolvimento do projeto Censo de Arquivos Brasileiros: Públicos e Privados, em parceria com o Ministério da Cultura da Espanha. A ideia de se realizar um grande censo das instituições arquivísticas de caráter público e privado havia sido proposta na I Mesa Redonda Nacional de Arquivos, em 1999. No ano 2001 foi concluída a primeira etapa, que resultou no cadastramento de 1.350 fundos/coleções em posse de trinta diferentes instituições (ARQUIVO NACIONAL, 2001; COSTA, 2003). O desenvolvimento desse trabalho possibilitou a implantação do Sistema de Informações do Arquivo Nacional (SIAN), que atualmente incorpora 829 fundos publicados e 574.767 registros disponíveis para consulta pública no Portal Institucional do Arquivo Nacional (ARQUIVO NACIONAL, 2011). 
Em 2009 foi instituído o Cadastro Nacional de Entidades Custodiadoras de Acervos Arquivísticos, por meio da Resolução $\mathrm{n}^{\circ}$ 28, de 17 de fevereiro. O objetivo do cadastro é fornecer acesso à missão institucional, aos acervos e contatos das diversas instituições arquivísticas existentes no País. Por meio desse cadastro, as instituições públicas e privadas detentoras de arquivos são registradas e obtêm o Código de Entidades Custodiadoras de Acervos Arquivísticos (CODEARQ), utilizado para identificar de maneira inequívoca cada uma das entidades. Esse código, no entanto, somente é fornecido se a instituição custodiadora permitir o acesso público aos seus acervos, mesmo existindo restrição de acesso a alguns documentos (CONSELHO NACIONAL DE ARQUIVOS, 2009).

Todos esses esforços do poder público no sentido de mapear os arquivos existentes são de grande louvor, mas ainda compreendem iniciativas gerais que abrangem todos os conjuntos de arquivos públicos e privados. Não se encontrou registro de ações específicas voltadas aos arquivos empresariais, mas é possível estender a eles todas as críticas direcionadas aos arquivos em geral. Os arquivos empresariais, em razão de suas especificidades e crescente importância para a pesquisa histórica e social, certamente demandam maiores investimentos públicos em termos de orientação e fomento de iniciativas de resgate e criação de repositórios, desenvolvimento de projetos de identificação e descrição dos conteúdos desses acervos e estabelecimento de canais de acesso e divulgação das informações registradas nos documentos preservados.

\section{Arquivos Privados e Particulares}

Quando se considera a necessidade de preservação da história, dos registros, artefatos e arquivos históricos relativos aos acontecimentos ocorridos em determinado tempo e local, não é raro, no caso dos arquivos das empresas brasileiras, que se leve em conta desde logo o papel central ocupado pelo Estado. Na medida em que esses documentos não compreendem exclusivamente informações relativas a determinadas empresas isoladas, mas oferecem também canais de acesso ao conhecimento da história mais ampla, de interesse regional ou nacional, existe certa tendência em atribuir ao poder público a responsabilidade pelo desenvolvimento de atividades de guarda e preservação desse conjunto de informações. No entanto, a própria legislação brasileira distingue entre arquivos públicos e privados e estabelece por meio de categoria intermediária, a de arquivos privados de interesse público, a responsabilidade de certos particulares preservarem seus arquivos.

Para além dos arquivos compreendidos por esta última classificação, existe grande necessidade de se analisar a relevância dos arquivos privados que permanecem ao largo da declaração estatal que os define como sendo de interesse para a História do Brasil ou para a sociedade brasileira. Esses arquivos são tão importantes quanto ou até mais do que aqueles declarados de interesse público; e deveriam, portanto, ser obrigatoriamente preservados. Os arquivos privados, em poder de indivíduos e empresas particulares, encerram grande riqueza para os historiadores de empresas, na medida em que possibilitam o acesso a uma miríade de dados e informações que permitem desvelar fatos cotidianos, informações não publicadas, padrões e percursos de decisão e ação, além de uma série de outras análises que não seriam possíveis por meio da utilização única de fontes oficiais ou de acesso amplo.

Assim, ao lado da atuação governamental, é fundamental a atuação de uma série de empreendimentos e organizações privadas que desenvolvam atividades de resgate, preservação e disponibilização de fontes para a pesquisa empresarial. Verifica-se, desse modo, a permanente atuação de instituições arquivísticas tradicionais, como, em São Paulo, do Cedic, da PUC-SP; do Centro de Documentação e Memória (Cedem), da Unesp; e do Arquivo Edgard Leuenroth, da Unicamp. No Rio de Janeiro, CPDOC; Fundação Casa de Rui Barbosa; Casa de Oswaldo Cruz (HEYMANN, 2005). No que concerne à atuação empresarial particular, é possível apontar o Núcleo de Memória Odebrecht, o Centro de Memória Bunge, o Memória Globo, o Memória Votorantim, o Projeto Memória Bosch, o Espaço Memória Pão de Açúcar, o Centro de Memória Natura, o Memória Petrobras, entre outros (FIGUEIREDO, 2009). 
No entanto, a indisponibilidade e inexistência de arquivos e fontes históricas para pesquisa nas empresas, em virtude do desconhecimento e desinteresse dos gestores, é discussão perene na literatura, assim como a dificuldade de acesso a informações e documentos existentes, principalmente nos países emergentes (AMATORI e JONES, 2003; CABERO, 1997; PIERANTI, 2008). Entre as principais causas para isso, inclui-se certa visão geralmente estabelecida quanto aos arquivos serem meramente repositórios do passado da organização, característicos das formas mais ultrapassadas de burocracia, e aos seus gestores caberem preocupações voltadas à atualidade das operações e ao planejamento das ações futuras da empresa. A essa visão parcial da finalidade dos arquivos, Mundet (2001) apresenta algumas das diversas funções desempenhadas por eles nas empresas, entre as quais é possível citar:

- suporte à gestão, na qualidade de ferramenta essencial para aumentar a eficiência organizacional por meio da redução de custos e gestão das informações;

- documentação, preservação e prestação de contas exigidas pela legislação e pelos órgãos públicos no serviço legal e público;

- atendimento às necessidades gerais da empresa, que envolve o registro e o arquivo de informações sobre as diversas atividades, eventos e projetos desenvolvidos pela empresa;

- fonte de informação, como repositório do conhecimento, experiência e competência geradas na organização.

$\mathrm{Na}$ visão do autor, os arquivos ainda contribuem para: a manutenção da continuidade da organização, visto que os documentos preservados são evidências que permitem estabelecer os elos entre o passado e o presente da empresa; a promoção da comunicação e identidade organizacionais, por meio da preservação das informações e documentos fundamentais e da superação de barreiras departamentais internas; o aumento da eficiência por meio da redução do tempo na busca de informações; a garantia da segurança e permanência das informações e conservação da história da empresa, além do fornecimento de suporte às atividades de gestão da qualidade e inovação organizacional (MUNDET, 2001).

Mesmo considerando a falta de consciência dos gestores em relação aos benefícios apontados por Mundet (2001), ocorre que nos últimos anos tem-se verificado grande crescimento na quantidade de projetos dedicados à preservação da história das empresas brasileiras. Apesar de serem ainda recentes essas iniciativas no cenário nacional, a implantação e utilização de arquivos pelas empresas têm sido apontadas como mudanças irreversíveis. Seja por influência dos sistemas de normas ISO, seja pela intenção da organização em explorar elementos de gestão da informação, do conhecimento e da comunicação organizacional ou pela preocupação em resgatar a história e desenvolver a identidade da organização, tem sido expressivo o crescimento na quantidade de empresas que se têm dedicado à construção de projetos de resgate da memória e à construção de museus e acervos empresariais nacional e internacionalmente (MENDES, 2002; MUNDET, 2001; NASSAR, 2004; VALDALISO e LÓPEZ, 2003).

Em sua maioria, essas iniciativas são desenvolvidas em razão de interesses comemorativos e estão associadas a estratégias de fortalecimento da identidade organizacional perante os funcionários da organização e ações de responsabilidade social e construção da imagem empresarial em face do público externo da empresa. Entre as metodologias empregadas no desenvolvimento destes projetos, a história oral apresenta-se como a principal técnica para o levantamento e obtenção de informações sobre o percurso histórico da organização. No que concerne aos elementos documentais e de arquivo, há ênfase no resgate e exposição de registros fotográficos, construção de centros de memória empresarial e outros projetos correlatos (NASSAR, 2004; TORTELLA, 2003).

Cada vez mais esses projetos configuram alternativas importantes à dependência dos investimentos públicos na criação e preservação de arquivos e destacam-se como fontes fundamentais para a realização de pesquisas sobre a história das organizações. No entanto, essas iniciativas podem tornar-se também fontes de dificuldades para a pesquisa histórica. Em primeiro lugar, em virtude de as atividades de arquivo serem 
altamente dependentes do desempenho do negócio e dos fluxos financeiros da organização. Em segundo, porque, na medida em que tendem a constituir, em sua maioria, ações isoladas desenvolvidas por particulares visando ao resgate do seu próprio histórico e com pouco interesse em visualizar a história mais ampla, dos concorrentes ou do setor de atuação, o trabalho de coleta e preservação dos documentos pode ficar restrito unicamente aos aspectos relativos a uma única organização. A literatura apresenta também grande preocupação com a possibilidade de vieses na montagem dos acervos e, principalmente, no desenvolvimento de pesquisas em História Empresarial envolvendo grande proximidade e patrocínio das organizações interessadas (BARJOT, DAUMAS e FRIDENSON, 2009; DALLA COSTA, 2004; ERRO e CAPISTEGUI, 2003).

Além dos problemas que se refletem na realização das pesquisas históricas, há que se ver as dificuldades próprias à gestão dos arquivos nas organizações, que envolvem (SILVA, 2010, p. 30):

[...] a inexistência de uma política de arquivos; o tratamento técnico inadequado; um sistema inadequado ou mal estruturado para a recuperação das informações; a ausência de investimentos; a falta de recursos humanos qualificados; a ausência de critérios de avaliação dos documentos; o aumento da massa documental produzida e a redução do espaço físico para a guarda de documentos [e o fato de] nem sempre o setor [ser] considerado pelos administradores como fonte de informação estratégica [ou] prioritário dentro das metas da empresa.

No que concerne ao trabalho a ser desenvolvido, apesar de a gestão de arquivos empresariais ser similar à gestão de qualquer outro tipo de arquivo, possui algumas características que a diferenciam nos âmbitos público e privado. Entre os principais elementos, Mundet (2001) apresenta: a estrutura das empresas, que em sua maioria são microempresas e não possuem funcionários; os requisitos legais, que demandam a preservação de documentos relativos à autorização de funcionamento da empresa (contábeis, fiscais, entre outros) e não de organização documental; as funções documentais, que implicam diferenças na publicidade dos documentos com função informativa, ou seja, que perderam sua função probatória ou relativa aos direitos e obrigações da empresa; e a visão dos arquivos como unidade logística ou de apoio dentro da empresa, que engloba a visão destes como meros prestadores de serviço de guarda e recuperação de informações para outros departamentos ou sua utilização estratégica para auxiliar na consecução dos objetivos da organização.

Outra situação diretamente associada com os arquivos privados e, principalmente, nos casos em que a responsabilidade pela preservação dos documentos e pela manutenção dos arquivos permanece a cargo dos particulares, envolve a questão de acesso aos registros e documentos das organizações. Por um lado, existem várias dificuldades associadas com os documentos de caráter confidencial e com a questão da abertura e dos prazos para divulgação das informações contidas nessa documentação. Por outro lado, os arquivos continuam sendo compreendidos como bens privados e, portanto, sujeitos aos humores e ingerências dos seus proprietários, aos quais reside a determinação última quanto à disponibilização dos documentos e informações aos pesquisadores. Em razão disso, Costa (2003) atribui ao Estado a responsabilidade pela criação de medidas legais voltadas a estimular os proprietários de arquivos a oportunizá-los para a realização de pesquisas.

O interesse no fortalecimento dos programas de preservação e dos empreendimentos dedicados aos arquivos empresariais brasileiros demanda que sejam equacionadas as possibilidades de contribuição desses agentes de modo a integrar seus esforços na construção de grandes projetos e programas dedicados a recuperar documentos e registros sobre a história das organizações brasileiras, reunir e organizar adequadamente esses registros em coleções e arquivos bem estruturados e acondicionados e integrar os acervos das diversas instituições dedicadas aos arquivos empresariais, fornecendo acesso para a realização de pesquisas. Essa é etapa necessária e fundamental para garantir a disponibilidade de matéria-prima para pesquisas dedicadas a desvendar a história das empresas e do desenvolvimento da Administração no Brasil. 


\section{Considerações Finais}

No presente ensaio, argumentou-se que, a fim de que se efetivem os clamores quanto à necessidade de aproximação entre Estudos Organizacionais e História e para que seja possível a realização de pesquisas sobre a Administração mediante perspectiva histórica, faz-se necessária a existência de registros, de arquivos que encerrem documentos e informações relativos à História Empresarial e à participação das empresas e empresários na construção da história nacional. Com base nessas informações, passou-se à análise do panorama atual dos arquivos brasileiros, procurando-se discorrer sobre o processo de evolução recente, a legislação que embasa o funcionamento do setor, a estrutura pública de gerenciamento dos arquivos, as condições infraestruturais e os recursos necessários para a operação dos arquivos existentes.

O caso dos arquivos empresariais brasileiros é similar àquele constatado em outras experiências internacionais, que indicam a existência de um contínuo entre dois extremos: o primeiro é fundamentado na atuação centralizada do Estado, que se responsabiliza pela organização e preservação dos documentos produzidos pelas empresas; e o segundo, dependente da atuação interessada das empresas e de grupos empresariais que se disponham a desenvolver projetos e arcar com os investimentos e custos necessários para recuperar registros e informações e criar espaços adequados para manter os acervos e documentos relativos à sua história (TORTELLA, 2003).

A apreciação do caso brasileiro mostrou que não existe divisão muito clara e estabelecida entre os deveres do Estado e das empresas privadas no que concerne à preservação dos arquivos empresariais. Os arquivos privados de maior importância para a legislação são aqueles declarados de interesse público e social, no entanto, essa atribuição não leva a que o poder público se responsabilize pela guarda e preservação dos documentos, que permanecem com o dono ou detentor do arquivo. Outra forma de encarar a situação envolve a documentação das empresas privatizadas, cujos registros anteriores à privatização são de interesse público, mas o encargo do gerenciamento e manutenção do arquivo muitas vezes permanece com a empresa adquirente. Uma terceira situação que sinaliza esse compartilhamento de responsabilidades pode ser encontrada no âmbito dos arquivos públicos estaduais e municipais, no qual, não raro, é possível encontrar seção dedicada a arquivos privados que reúne documentos de empresas da região preservados e incluídos no acervo (CONSELHO NACIONAL DE ARQUIVOS, 1998).

Além da importância intrínseca dos programas de resgate da história e memória corporativas, há que se considerar também o valor dos projetos que redundam no estabelecimento de entidades ou unidades administrativas dedicadas a organizar e preservar os arquivos recuperados. Essas iniciativas, na sua quase exclusiva totalidade, são dependentes das intenções e interesses das próprias empresas que as desenvolvem, visto que são praticamente inexistentes os incentivos governamentais destinados a financiar a preservação da história das empresas brasileiras por empreendimentos privados. No entanto, essas práticas trazem como prejuízo a tendência de ficarem restritas aos documentos e artefatos referentes unicamente àquela empresa específica que mantém o centro ou programa, com pouco investimento na agremiação de documentos referentes a outras empresas ou que possuem importância social mais ampla - ainda que esses não sejam objetivos precípuos dos projetos desenvolvidos pela empresa.

Desse modo, na medida em que a preocupação com a preservação da história empresarial não se restringe, mas perpassa as próprias organizações sujeitos dessa história, faz-se necessário o desenvolvimento de mecanismos que permitam reunir e organizar significativamente os vestígios que encerram a história das empresas, de modo que, quando se realizem as pesquisas acadêmicas, estas não fiquem restritas, por falta de alternativa outra, à compreensão da História como produto exclusivo de um grupo seleto de organizações e gestores, mas se lhes permitam explorar ao máximo a complexidade dos acontecimentos mediante informações que os registros encerram, estejam eles em poder de particulares ou disponíveis para a consulta pública. Para tanto, faz-se necessário não somente a existência de arquivos públicos e privados dedicados à coleta, preservação e sistematização desses materiais, como também se demanda a disponibilização do acesso e dos recursos necessários para que os pesquisadores possam desenvolver as suas análises. 


\section{Referências}

AMATORI, F.; JONES, J. Introduction. In: AMATORI, F.; JONES, J. Business history around the world. Cambridge: Cambridge University Press, 2003.

ARAÚJO, A. M. C.; BATALHA, C. H. M. Preservação da memória e pesquisa: a experiência do arquivo Edgard Leuenroth (AEL). In: SILVA, Z. L. da (Orgs.). Arquivos, patrimônio e memória: trajetórias e perspectivas. São Paulo: UNESP, 1999. p. 65-77.

ARQUIVO NACIONAL. Base de dados censo de arquivos brasileiros: públicos e privados. 2001. Disponível em: <http://www.portalan.arquivonacional.gov.br/media/Projeto\%20Censo-\%20Publique\%20final.pdf>. Acesso em 24 jan. 2011.

- Sistema de Informações do Arquivo Nacional - SIAN. Disponível em:

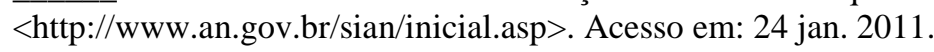

BARJOT, D.; DAUMAS, J.; FRIDENSON, P. Débat: les archives d'entreprises: ressource potentielle ou nouvelle contrainte? Entreprises et Histoire, n. 55, p. 111-123, 2009.

BELÉM, F. M. A gestão sistêmica de arquivos a partir da análise dos sistemas estaduais de São Paulo e Rio Grande do Sul. 2009. 99f. Monografia (Bacharelado em Arquivologia) - Universidade Federal do Rio Grande do Sul, Porto Alegre, 2009.

BOOTH, C.; ROWLINSON, M. Management and organizational history: prospects. Management \& Organizational History, v. 1, n. 5, p. 5-30, 2006.

BRASIL. Lei $n^{\circ}$ 8.159, de 08 de janeiro de 1991. In: CONSELHO NACIONAL DE ARQUIVOS. Legislação Arquivística Brasileira, fev. 2010.

. Decreto $\mathrm{n}^{\circ}$ 4.073, de 3 de janeiro de 2002. In: CONSELHO NACIONAL DE ARQUIVOS. Legislação Arquivística Brasileira, fev., 2010.

BRESSER PEREIRA, L. C. Empresários e administradores no Brasil. São Paulo: Brasiliense, 1974.

CABERO, M. M. El archivo de empresa: un recurso a considerar desde la perspectiva TQM (Total Qualíty Management). Revista General de Información y Documentación, v. 7, n. 2, p. 257-275, 1997.

CAMPELLO, C. O estudo sobre empresários e empresas: conceito, relevância e panorama historiográfico. Revista Tema Livre, n. 10, 2005. Disponível em: 〈http://www.revistatemalivre.com/empresas10.html〉. Acesso em: 27 maio 2009.

CARDOSO, F. H. Empresário industrial e desenvolvimento econômico. São Paulo: DIFEL, 1964.

CHANDLER JR., A. D. Strategy and structure: Chapters in the history of the American industrial enterprise. Cambridge: Harvard University Press, 1962.

1977.

. The visible hand: The managerial revolution in American business. Cambridge: Harvard University Press,

Scale and scope: The dynamics of industrial capitalism. Cambridge: Harvard University Press, 1990.

CLARK, P.; ROWLINSON, M. The treatment of history in organisation studies: towards an 'historic turn'? Business History, v. 46, n. 3, p. 331-352, 2004.

COCHRAN, T. C. Business in American history. Business History Conference, v. 1, Michigan State University, 1962. Proceedings... Disponível em: <http://www.h-net.org/ business/bhcweb/publications/BEHprint/v01A/cochran.pdf>. Acesso em: 22 jul. 2009. 
COLE, A. H. What is business history? The Business History Review, v. 36, n. 1, p. 98-106, 1962.

CONSELHO NACIONAL DE ARQUIVOS. Subsídios para a implantação de uma política municipal de arquivos: o arquivo municipal a serviço dos cidadãos. Rio de Janeiro: CONARQ, 1998.

$$
\text { Resolução } \mathbf{n}^{\mathbf{0}} \mathbf{2 8} \text {, de } 17 \text { de fevereiro de } 2009 \text {. Disponível em: }
$$

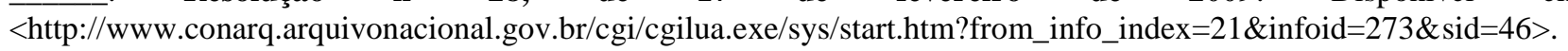
Acesso em: 25 jan. 2011.

COSTA, A. M. da; BARROS, D. F.; MARTINS, P. E. M. Perspectiva histórica em administração: panorama da literatura, limites e possibilidades. In: ENCONTRO DA ANPAD, 33, 2009, São Paulo. Anais... Rio de Janeiro: ANPAD, 2009. CD-ROM.

COSTA, C. M. L. Acesso à informação nos arquivos brasileiros: retomando a questão. Estudos Históricos, n. 32, p. 178-188, 2003.

CURADO, I. Pesquisa historiográfica em administração: uma proposta metodológica. In: ENCONTRO DA ANPAD, 25, 2001, Campinas. Anais... Rio de Janeiro: ANPAD, 2001. CD-ROM.

DALLA COSTA, A. J. História e historiografia empresarial: acesso e utilização de arquivos e fontes. In: DALLA COSTA, A. J.; GRAF, M. E. de C. Estratégias de desenvolvimento urbano e regional. (Orgs.). Curitiba: Juruá, 2004. p. $121-141$.

ERRO, C.; CASPISTEGUI, F. J. Empresarios e historia empresarial. Algunas claves para um mutuo acercamiento. In: ERRO, C. Historia empresarial: pasado, presente y retos de futuro. Barcelona: Ariel, 2003. p. 173-202.

FIGUEIREDO, M. C. Da memória dos trabalhadores à memória Petrobras: a história de um projeto. 109 f. 2009. Trabalho de Conclusão de Curso (Mestrado em Bens Culturais e Projetos Sociais) - Centro de Pesquisa e Documentação de História Contemporânea do Brasil - CPDOC. Rio de Janeiro: Fundação Getúlio Vargas, 2009.

FORJAZ, M. C. S. História empresarial como área de pesquisa. Relatório de pesquisa no 14/2008, EAESP/FGV. Disponível em: <http://www.eaesp.fgvsp.br/AppData/GVPesquisa/Rel142008.pdf>. Acesso em 30/04/2011.FUNDACIÓN HISTÓRICA TAVERA. Brasil: primer borrador de informe sobre la situación del patrimonio documental de América Latina. Madrid: Banco Mundial, 1999.

GRAS, N. S. B. Why study business history. The Canadian Journal of Economic and Political Science, v. 4, n. 3, p. 320-340, 1938.

GUERREIRO RAMOS, A. Administração e contexto brasileiro: esboço de uma teoria geral da Administração. Rio de Janeiro: Fundação Getulio Vargas, 1983.

HARVEY, C.; WILSON, J. Redefining business history: an editorial statement. Business History, v. 49, n. 1, p. 1-7, 2007.

HEYMANN, L. Q. Velhos problemas, novos atores: desafios à preservação dos arquivos privados. In: SEMINÁRIO PRESERVAÇÃO DO PATRIMÔNIO CULTURAL E UNIVERSIDADE, São Paulo, 2005. Anais... Centro de Pesquisa e Documentação de História Contemporânea do Brasil: São Paulo, p. 1-7, 2005.

ICHIKAWA, E. Y.; SANTOS, L. W. de. Contribuições da história oral à pesquisa organizacional. In: GODOI, C. K.; BANDEIRA-DE-MELLO, R.; SILVA, A. B. de (Orgs.). Pesquisa qualitativa em estudos organizacionais: paradigmas, estratégias e métodos. São Paulo: Saraiva, 2006.

JARDIM, J. M. O acesso à informação arquivística no Brasil: problemas de acessibilidade e disseminação. In: ARQUIVO NACIONAL. Mesa redonda nacional de arquivos. Rio de Janeiro: Arquivo Nacional, 1999. 
Políticas públicas de informação: a (não) construção da política nacional de arquivos públicos e privados (1994-2006). In: ENCONTRO NACIONAL DE PESQUISA EM CIÊNCIA DA INFORMAÇÃO, 9, 2008 , São Paulo. Anais... São Paulo: ECA/USP, p. 1-17, 2008.

- O arquivo (vivo?) da nação. Jornal da Ciência. Disponível em: <http://www.jornaldaciencia.org.br/Detalhe.jsp?id=76022>. Acesso em: 24 jan. 2011.

KIESER, A. Why organization theory needs historical analyses - and how this should be performed. Organization Science, v. 5, n. 4, p. 608-620, 1994.

KIPPING, M.; ÜSDIKEN, B. Business history and management studies. In: JONES, G.; ZEITLIN, J. The Oxford handbook of business history. Oxford: Oxford University Press, 2008. p. 96-119.

LAWRENCE, B. S. Historical perspective: using the past to study the present. Academy of Management Review, v. 9, n. 2, p. 307-312, 1984.

LEVY, M. B. História da Bolsa de Valores do Rio de Janeiro. Rio de Janeiro: IBMEC, 1977.

A indústria do Rio de Janeiro através de suas sociedades anônimas. Esboços de história empresarial. Rio de Janeiro: Editora UFRJ, 1994.

MARTINS, P. E. M. A reinvenção do sertão: a estratégia organizacional de canudos. Rio de Janeiro: FGV Editora, 2001.

MENDES, J. A. Problemas de história empresarial: teoria e prática. In: ENCONTRO DA ASSOCIAÇÃO PORTUGUESA DE HISTÓRIA ECONÓMICA E SOCIAL, Aveiro, 22., 2002. Anais... Associação Portuguesa de História Económica e Social, Aveiro, 2002.

MENDONÇA, L. E. C. de. História de empresas brasileiras: tem espaço na academia? Questionamentos exploratórios e conclusões preliminares. Revista Eletrônica de Administração, v. 7, n. 4, jul./ago., 2001.

MUNDET, J. R. C. Archivo y empresa: más allá de la historia. Transportes, Servicios y Telecomunicaciones, n. 1, p. 187-206, 2001.

NASSAR, P. (Org.). Memória de empresa: história e comunicação de mãos dadas, a construir o futuro das organizações. São Paulo: Aberje, 2004.

PIERANTI, O. P. A metodologia historiográfica na pesquisa em administração: uma discussão acerca de princípios e de sua aplicabilidade no Brasil contemporâneo. Cad. EBAPE.BR, v. 6, n. 5, mar. 2008.

ROBERTS, A. La teoría en la historia empresarial. In: ERRO, C. Historia empresarial: pasado, presente y retos de futuro. Barcelona: Ariel, 2003. p. 57-80.

SCOTT, W. R. Organizations: rational, natural, and open systems. Upper Saddle River: Pearson, 2003.

SILVA, M. L. R. da. História e memória do arquivo central da FGV. 161 f. 2010. Trabalho de Conclusão de Curso (Mestrado em Bens Culturais e Projetos Sociais) - Centro de Pesquisa e Documentação de História Contemporânea do Brasil - CPDOC. Rio de Janeiro: Fundação Getúlio Vargas, 2010.

SZMRECSÁNYI, T. Retomando a questão do início da historiografia econômica no Brasil. Nova Economia, v. 14, n. 1, p. 11-37, 2004.

TORTELLA, T. Los archivos empresariales. Su organización, conservación y uso. In: ERRO, C. Historia empresarial: pasado, presente y retos de futuro. Barcelona: Ariel, 2003. p. 135-152.

TUCHMAN, G. Historical social science: methodologies, methods, and meanings. In: DENZIN, N. K.; LINCOLN, Y. S. Strategies of qualitative inquiry. Thousand Oaks: Sage, 1998. p. 225-260. 
ÜSDIKEN, B.; KIESER, A. Introduction: history in organization studies. Business History, v. 46, n. 3, p. 321-330, 2004.

VALDALISO, J. M.; LÓPEZ, S. ¿Sirve para algo la historia empresarial? In: ERRO, C. Historia empresarial: pasado, presente y retos de futuro. Barcelona: Ariel, 2003. p. 37-56.

VIZEU, F. Em algum lugar do passado: contribuições da pesquisa histórica para os estudos organizacionais brasileiros. In: ENCONTRO DA ANPAD, 31, 2007, Rio de Janeiro. Anais... Rio de Janeiro: ANPAD, 2007.

Management no Brasil em perspectiva histórica: o projeto do IDORT nas décadas de 1930 e 1940. $254 f$. 2008. Tese (Doutorado em Administração) - Fundação Getulio Vargas, 2008.

Potencialidades da análise histórica nos estudos organizacionais brasileiros. Revista de Administração de Empresas, v. 50, n. 1, p. 37-47, 2010.

WEBER, M. Economia e sociedade. 3. ed. Brasília: Editora da UnB, 1998. 2v.

ZALD, M. N. History, sociology and theories of organization. In: JACKSON, J. E. Institutions in American society: essays in market, political, and social organizations. Ann Arbor: University of Michigan Press, 1989. p. 81-108. 